\title{
Evidence showing the relationship between sagittal balance and clinical outcomes in surgical treatment of degenerative spinal diseases: a literature review
}

\author{
Jean-Charles Le Huec • Antonio Faundez • \\ Dennis Dominguez • Pierre Hoffmeyer • \\ Stéphane Aunoble
}

Received: 24 July 2014 / Accepted: 21 August 2014 / Published online: 6 September 2014

(C) The Author(s) 2014. This article is published with open access at Springerlink.com

\begin{abstract}
The measure of radiographic pelvic and spinal parameters for sagittal balance analysis has gained importance in reconstructive surgery of the spine and particularly in degenerative spinal diseases (DSD). Fusion in the lumbar spine may result in loss of lumbar lordosis (LL), with possible compensatory mechanisms: decreased sacral slope (SS), increased pelvic tilt (PT) and decreased thoracic kyphosis (TK). An increase in PT after surgery is correlated with postoperative back pain. A decreased SS and/or abnormal sagittal vertical axis (SVA) after fusion have a higher risk of adjacent segment degeneration. High pelvic incidence (PI) increases the risk of sagittal imbalance after spine fusion and is a predictive factor for degenerative spondylolisthesis. Restoration of a normal PT after surgery is correlated with good clinical outcome. Therefore, there is a need for comparative prospective studies that include pre- and postoperative spinopelvic parameters and compare complication rate, degree of disability, pain and quality of life.
\end{abstract}

Keywords Sagittal balance $\cdot$ Lumbar lordosis $\cdot$ Spinopelvic parameters $\cdot$ Degenerative spinal disease $\cdot$ Lumbar degenerative disc disease $\cdot$ Degenerative spondylolisthesis $\cdot$ Spine fusion

\section{Introduction}

Degenerative spine disease comprises a group of conditions characterised by loss of normal spinal structure and function,

J.-C. Le Huec $(\bowtie) \cdot$ S. Aunoble

Spine Unit 2, Surgical Research Lab, Bordeaux University Hospital, Bordeaux 33076, France

e-mail: j-c.lehuec@u-bordeaux2.fr

A. Faundez $\cdot$ D. Dominguez $\cdot$ P. Hoffmeyer

Service de Chirurgie Orthopédique et Traumatologie de l'Appareil

Moteur, Geneva University Hospital, Geneva, Switzerland most frequently affecting the lumbar spine [1]. Spinal degeneration is mainly a consequence of physiologic aging and is a major cause of chronic disability. This condition encompasses lumbar degenerative disc disease (LDDD), spinal stenosis, degenerative spondylolisthesis, degeneration of facet joints and degenerative scoliosis [2].

Over the past 15 years, sagittal balance analysis has gained importance in reconstructive surgery of the spine [3]. Indeed, many studies in healthy individuals have shown the importance of spinal sagittal balance and spinopelvic angulation [4-8]. With the increasing use of vertebral fusion, deleterious effects of surgery on sagittal balance have been reported [8-12]. These effects on sagittal balance are related to the locked position of the fused vertebra; the consequence of fixed sagittal imbalance is a loss of normal lumbar curvature, with forward inclination of the trunk [9-12]. Moreover, postoperative pain is related to alterations of characteristic parameters of sagittal balance and spinopelvic angulation [8].

There is growing interest in the use of spinopelvic parameters to predict outcomes in patients with degenerative spinal disease (DSD) [13-16]. Therefore, the aim of this literature review on surgery of degenerative lumbar pathologies was to determine whether consideration of sagittal balance parameters (either during surgical planning or by restoring sagittal balance during surgery) is correlated with better results.

\section{Materials and methods}

Literature search

Literature search was based on the Medline database covering the years 1990-2013. Articles that contained relevant information for the review, namely, use of parameters of sagittal balance (pelvic and spine parameters) for surgery in DSD 
were selected. The search strategy included the following keywords in all fields using different combinations, with the Boolean operators OR and AND: sagittal balance, sagittal imbalance, spinopelvic alignment, pelvic tilt, sacral slope, sacral tilt, pelvic incidence, spinopelvic parameters, degenerative spine, degenerative lumbar disc disease, degenerative spondylolisthesis, degenerative kyphosis, degenerative scoliosis, and lumbar spinal stenosis. Publications on isthmic spondylolisthesis or tumours were excluded. Surgical techniques included posterior lumbar interbody fusion (PLIF), transforaminal lumbar interbody fusion (TLIF) and SmithPetersen osteotomy; transpedicular osteotomy, dynamic stabilisation and intervertebral disc arthroplasty were excluded from this literature search. Relevant articles in reference lists were also selected. Only articles in English and French languages were selected.

\section{Definition of parameters}

\section{Pelvic and spinal parameters}

Pelvic parameters: The pelvis is the foundation on which rests the spine. On a lateral view, the width of the pelvis is quantified by the pelvic incidence (PI) (Fig. 1 and Table 1). PI is an angle that is anatomically fixed and is specific for each individual. This angle does not change after adolescence. The pelvis can rotate around the femoral heads up to a certain limit. This rotation is characterised by the pelvic tilt (PT) (Fig. 1). When the pelvis rotates backwards (retroversion), PT increases; when the pelvis rotates forward (anteversion), PT decreases. The sacral slope (SS) is the compensatory angle of PT and characterises the S1 endplate position. PT, PI and SS are mathematically linked by the following formula: $\mathrm{PI}=\mathrm{PT}+\mathrm{SS}$.

Spinal parameters: The spine, which rests on the pelvis (first vertebra), has to adapt its form to stay in balance. Transition from lumbar lordosis (LL) to thoracic kyphosis (TK) is a point called the inflection point (Fig. 2). The inflection point is not necessarily located at $\mathrm{T} 12-\mathrm{L} 1$, as written by anatomy textbooks, but varies according to the value of PI; its location may range from T10 to L2 [17]. Based on the inflection point, the apex of the LL and orientation of the S1 endplate, Roussouly et al. defined two arches of lumbar lordosis: upper and lower [17]. The most important conclusion from this observation was that the greatest amount of LL was located in the lower lumbar arch (L4-S1) in all study participants and that the upper arch was fairly constant, at $\sim 21^{\circ}$ [17]. Acknowledging this is essential, because it means that the value of the lower lumbar arch angle influences the overlying spine. In addition, it has been demonstrated that $70 \%$ of the total LL is located between the L4-L5 and S1 vertebrae [17, 18]. As the most frequent targets of surgical treatment in the lumbar spine are the L4-S1 segments, it is imperative to include this information in treatment strategy.

\section{Results}

The articles selected from the literature search and analysed for balance parameters before and/or after surgery are described in three clinical settings: (1) LDDD; (2) LDDD with spondylolisthesis and (3) degenerative scoliosis (Table 2).

\section{Sagittal balance and LDDD before surgery}

Abnormal parameters of sagittal balance are observed in degenerative conditions, such as LDDD and low back pain (Fig. 3). It is important, however, to differentiate these conditions from age-related changes. Thus, in patients with low back pain compared with age-matched controls, Jackson et al. reported that total LL was decreased $\left(56.3^{\circ}\right.$ vs. $\left.60.9^{\circ}\right)$ and sacrum was more vertical (SS, $47.2^{\circ}$ vs. $50.4^{\circ}$ ) [19]. However, C7 plumbline and TK were similar to controls due to compensatory mechanisms (pelvic retroversion and/or increased SS) to compensate the loss of LL.

Compensatory mechanisms have been widely described by Barrey et al. [20]. Three stages were observed corresponding to the severity of the imbalance: balanced, balanced with
Fig 1 Pelvic parameters: $P T$ pelvic tilt, $S S$ sacral slope, $P I$ pelvic incidence

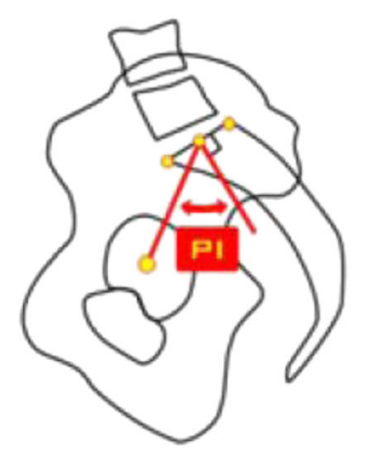

\section{$P I=P T+S S$}
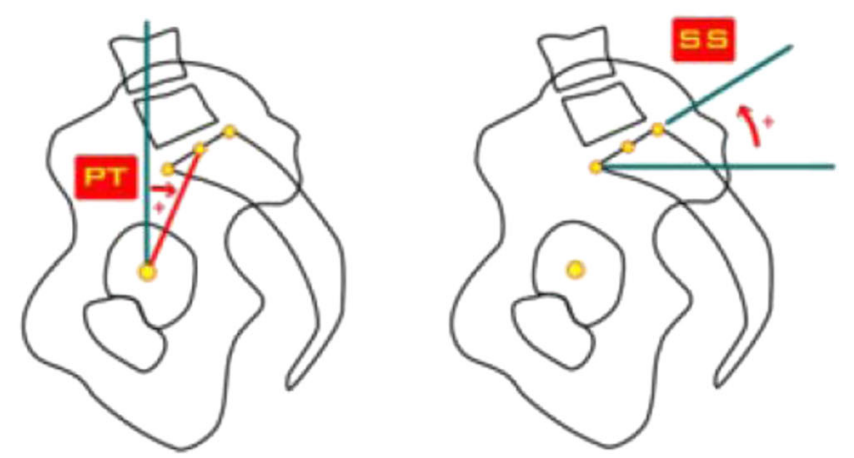
Table 1 Values of spinopelvic parameters in asymptomatic adults

* $\mathrm{PI}=\mathrm{PT}+\mathrm{SS}$

\begin{tabular}{ll}
\hline Parameter & Value \\
\hline Pelvic incidence (PI)* & $48-55^{\circ}$ \\
Pelvic tilt (PT) & $12-18^{\circ}$ \\
Sacral slope (SS) & $36-42^{\circ}$ \\
Lumbar lordosis (LL) & $43-61^{\circ}$ \\
C7 plumb line & $<3 \mathrm{~cm}$ \\
\hline
\end{tabular}

compensatory mechanisms and imbalanced. The consequences of loss of LL on global sagittal alignment are compensated and contribute to keep the sagittal balance. LDDD always showed loss of LL and its consequences on global balance and low back pain, confirming the fact that imbalance is a source of pain, Degenerative spondylolisthesis was described as a major factor of imbalance and degenerative scoliosis and was also always associated with compensated balance, with both situations being associated with back pain, thus suggesting that correcting the sagittal profile could improve back pain.

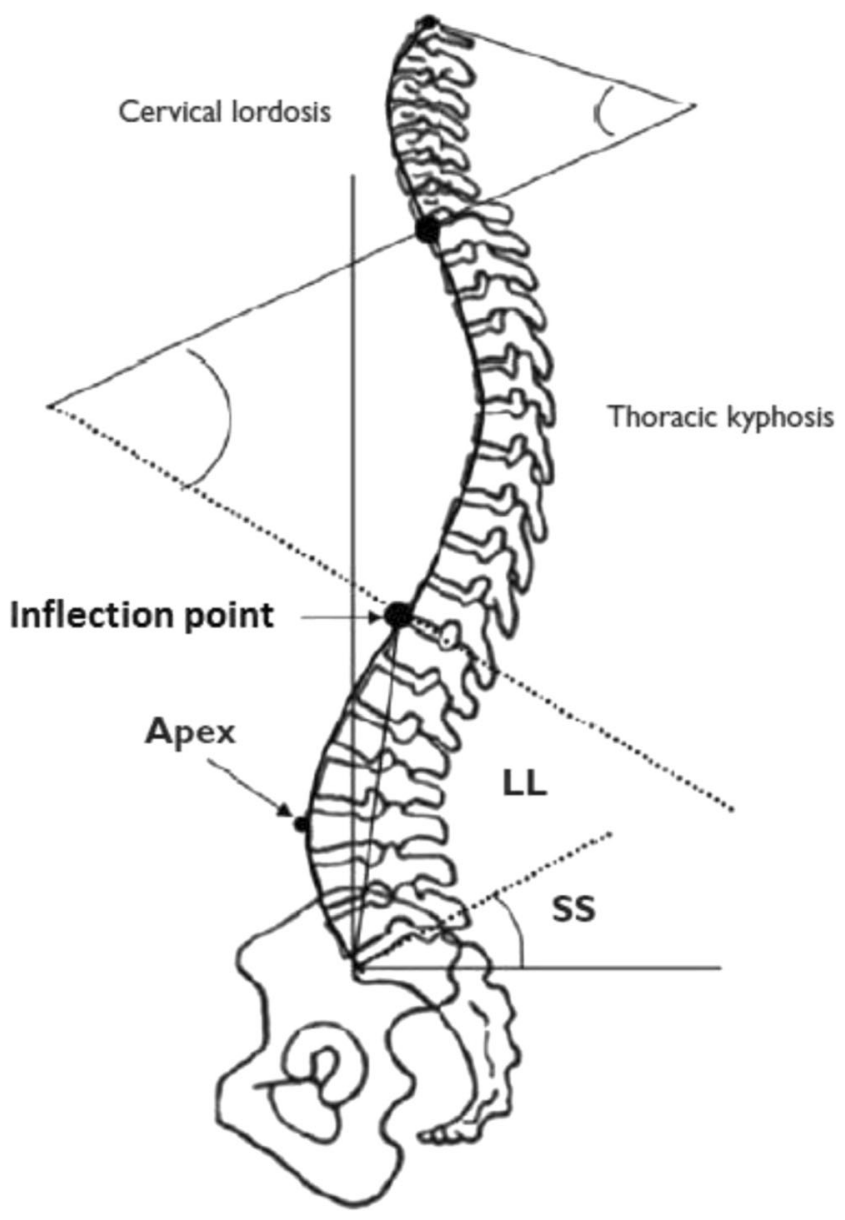

Fig 2 Spine segmentation and lumbar lordosis. Inflection points are the points of change in curvature and do not necessarily correspond to anatomical structures. Amplitudes of spinal curvature must be measured from these points. LL lumbar lordosis, SS sacral slope
Correlation between postoperative outcome of LDDD and restoration of sagittal balance

\section{Functional outcomes and sagittal balance}

Abnormal pre- and/or postoperative sagittal spinopelvic parameters are now widely recognised to affect clinical outcomes in spinal surgery, specifically spinal fusion. Early studies, published ten to 15 years ago, showed that lumbar fusion in DSD could lead to deleterious effects on sagittal spinal balance, including decreases in SS and LL [8, 10, 12, 21, 22]. For instance, the retrospective study by Tribus et al. 12 assessed radiological parameters in 28 patients undergoing posterior-spine fusions using the knee-chest position (Table 1). Indications for surgery were LDDD $(n=25)$, spondylolysis $(n=2)$ or discogenic back pain $(n=1)$. Spinal fusions were performed at L4-L5 in seven patients, L5-S1 in 13 and L4-S1 in eight. Average LL was unchanged before and after surgery (from $51^{\circ}$ to $50^{\circ}$ ). SS decreased significantly (from $49^{\circ}$ to $45^{\circ} ; p=0.039$ ) in the subgroup of patients undergoing L4-S1 spinal fusion, while it remained unchanged in the other subgroups. Although total LL was maintained, lordosis was shifted proximally in the lumbar spine, increasing at L1-L4 (from $19^{\circ}$ to $24^{\circ}$ ) and decreasing at L4-S1 from (from $32^{\circ}$ to $26^{\circ}$ ). Therefore, this study showed that postoperative sagittal alignment and compensatory mechanisms depended on surgical methods and fusion level.

Lazennec et al. compared pelvic parameters in 81 patients with or without pain after lumbosacral fusion (LDDD $n=44$, revision of lumbar fusion $n=13$, repeat surgery for disc herniation, $n=12$; other $n=12$ ) [8]. The subgroup with postfusion pain had, before surgery, a more vertical sacrum with decreased SS $\left(39.2^{\circ}\right.$ vs. $\left.45.7^{\circ} ; p<0.006\right)$ and an increased PT $\left(19.7^{\circ}\right.$ vs. $\left.12.4^{\circ} ; p<0.02\right)$. PT increase was correlated with persistent pain after fusion and was almost twice $\left(26.2^{\circ}\right)$ the normal value. SS in the standing position was also correlated with the presence of postfusion pain resulting from a sacrum that was abnormally vertical. These results suggest that failing to restore appropriate LL during surgery is associated with excessive PT, which is a cause of chronic pain: sagittal alignment resembles a sitting position with muscle tension and pain when maintaining the posture.

\section{Adjacent-segment degeneration and sagittal balance}

Some studies suggest that abnormal sagittal balance plays a significant role in degeneration of adjacent segments after lumbar fusion. Kumar et al. reviewed 83 patients with degenerative disc disease (degenerative spondylolisthesis, spinal stenosis or back pain due to disc degeneration) and studied the relation between abnormal sagittal-plane parameters of the lumbar spine and the development of adjacent-segment degeneration (spondylolytic spondylolisthesis and degenerative 
Table 2 Summary of studies describing sagittal alignment in surgery for degenerative spinal disease (DSD)

\begin{tabular}{lll}
\hline Study Design & Population & $\begin{array}{l}\text { Parameters of } \\
\text { sagittal balance }\end{array}$
\end{tabular}

Lumbar degenerative disc disease [12]
Lazennec et al. Retrospective study 81 patients with or without pain after (2000) [8] lumbosacral fusion (LDDD 44 patients).

Kumar et al. (2001) [21]
Tribus (1999) Retrospective study 28 patients who underwent posterior spine SS, ST LL,

Postoperative SS decreased for L4-S1 fusion. LL maintained (compensatory lordosis shifted proximally).

PI, SS, PT LL

\author{
(2001) [21]
}

\begin{tabular}{|c|c|c|}
\hline $\begin{array}{l}\text { Gödde et al. } \\
\text { (2003) [9] }\end{array}$ & $\begin{array}{l}\text { Comparative } \\
\text { retrospective } \\
\text { study }\end{array}$ & $\begin{array}{l}42 \text { patients with spinal stenosis or } \\
\text { degenerative spinal instability who } \\
\text { underwent fusion }\end{array}$ \\
\hline $\begin{array}{l}\text { Gottfried et al. } \\
\text { (2009) [23] }\end{array}$ & Retrospective study & $\begin{array}{l}15 \text { patients with DSD with postfusion } \\
\text { flat-back deformity }\end{array}$ \\
\hline $\begin{array}{l}\text { Jang et al. (2009) } \\
\text { [25] }\end{array}$ & Retrospective study & $\begin{array}{l}53 \text { patients with correction of lumbar } \\
\text { degenerative kyphosis }\end{array}$ \\
\hline $\begin{array}{l}\text { Cho et al. (2010) } \\
\text { [24] }\end{array}$ & Retrospective study & $\begin{array}{l}45 \text { patients after vertebral fusion for adult } \\
\text { lumbar degenerative scoliosis }\end{array}$ \\
\hline \multicolumn{3}{|c|}{ LDDD with spondylolisthesis } \\
\hline $\begin{array}{l}\text { Barrey et al. } \\
\text { (2007) [28] }\end{array}$ & $\begin{array}{l}\text { Retrospective } \\
\text { comparative } \\
\text { study }\end{array}$ & $\begin{array}{l}85 \text { patients with LDDD (disc herniation, } \\
\text { degenerative disc disease, } \\
\text { spondylolisthesis) and } 154 \text { controls }\end{array}$ \\
\hline $\begin{array}{l}\text { Barrey et al. } \\
\text { (2007) [29] }\end{array}$ & $\begin{array}{l}\text { Retrospective } \\
\text { comparative } \\
\text { study }\end{array}$ & $\begin{array}{l}40 \text { patients with degenerative } \\
\text { spondylolisthesis and } 154 \text { controls }\end{array}$ \\
\hline $\begin{array}{l}\text { Kim et al. (2011) } \\
\text { [30] }\end{array}$ & $\begin{array}{l}\text { Retrospective pilot } \\
\text { study }\end{array}$ & $\begin{array}{l}18 \text { patients with degenerative } \\
\text { spondylolisthesis who underwent } \\
\text { fusion surgery }\end{array}$ \\
\hline $\begin{array}{l}\text { Funao et al. } \\
\text { (2012) [35] }\end{array}$ & $\begin{array}{l}\text { Comparative } \\
\text { retrospective } \\
\text { study }\end{array}$ & $\begin{array}{l}\text { Patients undergoing surgery for lumbar } \\
\text { spinal canal stenosis: } 50 \text { patients with } \\
\text { degenerative spondylolisthesis and } 50 \\
\text { matched controls }\end{array}$ \\
\hline
\end{tabular}

Degenerative scoliosis
Lafage et al. Prospective study (2009) [32]

125 adult patients with spinal deformity: 33 adult de novo (degenerative) scoliosis, 29 iatrogenic sagittal imbalance, 54 adult idiopathic scoliosis, 9 others)
SS LL and segmental lordosis

PI, PT LL, TK

SS C7 plumb line, LL, TK

Decreased SS and PT twice the normal for patients with persistent postoperative pain after lumbosacral fusion.

Higher incidence of adjacent-segment degeneration during follow-up (5 years) in patients with abnormalities in immediate postoperative sagittal parameters (SS and C7 plumb line)

Fusion had impact on sagittal balance changes of SS according to cage geometry (either diminution of lordosis with compensatory changes of SS or increased lordosis).

Patients with postfusion flat back had elevated PI and inadequate LL; there was a pelvic retroversion to maintain sagittal balance

When appropriate LL was achieved, compensatory reduction in TK and increase in PT spontaneously reversed

PI, SS, PT C7 plumb Preoperative sagittal imbalance and high PI line, TK were risk factors for sagittal decompensation

PI, SS, PT, SSA C7 Patients with disc herniation and LDDD had PI plumb line, LL, TK similar to controls. Patients with degenerative spondylolisthesis had higher PI

PI, SS, PT LL, TK, Higher PI in patients with degenerative C7 plumb line spondylolisthesis. High PI could be a predisposing factor of degenerative spondylolisthesis

PI, SS, PT LL In patients with improved postoperative PT after fusion, clinical outcomes were good (pain VAS and Oswestry Disability Index).

PI, SS, PT L4 slope, Progression of vertebral slip could be related to L5 slope, LL, TK greater PI. The compensatory mechanisms appear different in patients with degenerative spondylolisthesis compared with matched controls

PI, PT, SS LL, TK

High PT (pelvic retroversion) was the compensatory mechanism for sagittal imbalance and was correlated with poor clinical outcome and quality of life (Owestry Disability Index, SF-12, Scoliosis Research Society)

$\begin{array}{ccc}\begin{array}{c}\text { Charosky et al. } \\ \text { (2012) [31] }\end{array} & \begin{array}{c}\text { Multicentric } \\ \text { retrospective } \\ \text { study }\end{array} & \begin{array}{c}306 \text { adult patients with primary } \\ \text { degenerative or idiopathic scoliosis } \\ \text { (lumbar or thoracolumbar) operated for } \\ \text { the first time. }\end{array} \\ \begin{array}{c}\text { Johnson et al. } \\ \text { (2013) [33] }\end{array} & \text { Prospective study } & \begin{array}{c}30 \text { patients with LDDD (15 with adult } \\ \text { degenerative scoliosis and 15 with } \\ \text { spondylosis) who underwent surgery }\end{array}\end{array}$

PI, SS, PT Among the risk factors for mechanical and neurological complications was a high preoperative $\mathrm{PT}\left(\geq 26^{\circ}\right)$

PI, SS, PT C7 plumb line, LL, TK
Clinical outcomes (VAS, Oswestry Disability Index, SF-36) were improved. Surgery did not change mean SS and PT. Scoliosis was improved

$H R Q O L$ health-related quality of life, $L L$ lumbar lordosis, $P I$ pelvic incidence, $P T$ pelvic tilt, $S S$ sacral slope, $S S A$ spinosacral angle, $T K$ thoracic kyphosis, $V A S$ visual analogue scale, $D S D$ degenerative spinal disease, $L D D D$ lumbar degenerative disc disease 


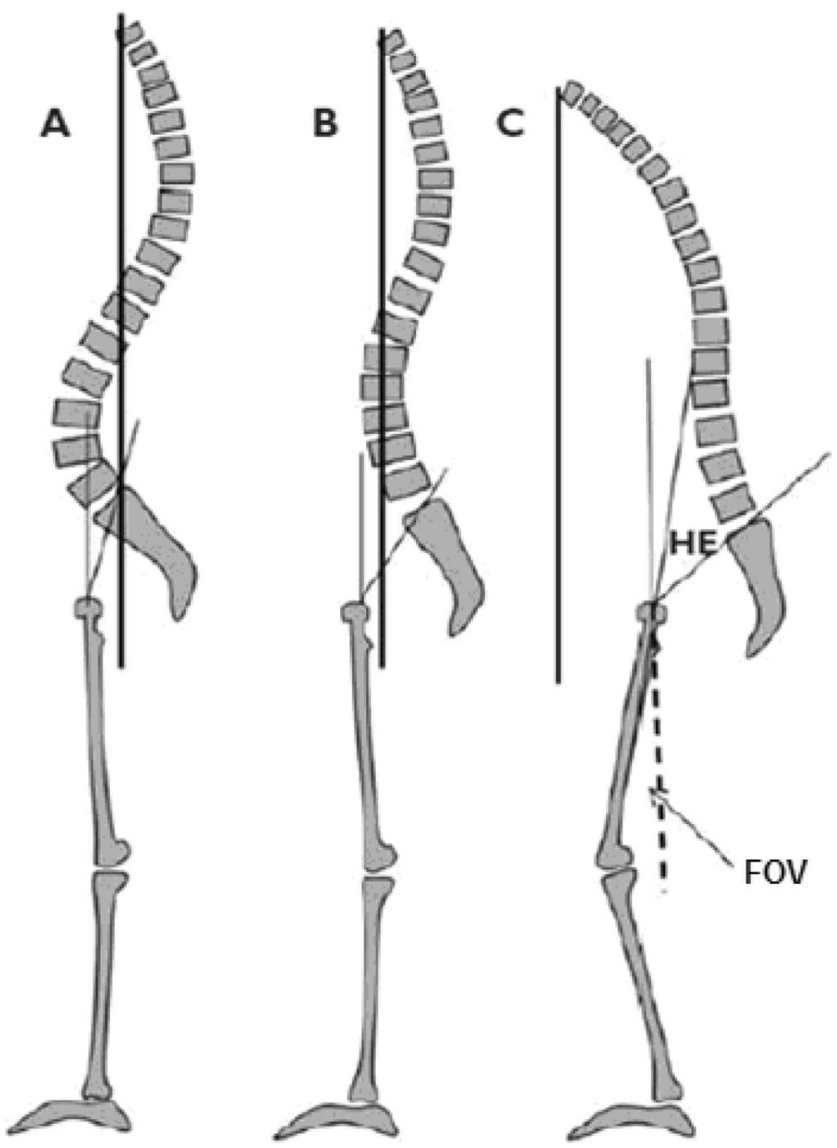

Fig 3 Compensation of spinal imbalance in degenerative spinal disorders. a. Normal balance; $\mathbf{b}$. Loss of lumbar lordosis and sagittal imbalance compensated by pelvis retroversion; $\mathbf{c}$. Neuromuscular control and pelvis retroversion are not sufficient to compensate sagittal imbalance, and the patient bends knees in order to bring back as posteriorly as possible the $\mathrm{C} 7$ plumb line. $H E$ hip extension, $F O V$ femur obliquity with vertical

scoliosis were not included) [21]. Radiographic evidence of adjacent-segment degeneration was observed in 41/83 (36.1\%) patients. Patients who had an abnormal C7 plumb line position (which usually intersects the sacral plate for patients in the standing position) and/or SS in the immediate postoperative radiographic follow-up had a significantly higher rate of adjacent-segment deterioration $(p<0.02)$.

Risk factors for postoperative sagittal imbalance

Flat-back, or kyphotic decompensation, syndrome can result from loss of lordosis after spinal fusion. Spinopelvic parameters, including determination of the optimal amount of LL, must be measured and taken into account before performing lumbar fusion in order to prevent fixed sagittal imbalance. In fact, Gottfried et al. evidenced a characteristic profile for spinopelvic parameters in 15 patients with DSD and postfusion fixed sagittal imbalance [23]. The latter had a high PI $\left(66.7^{\circ}\right)$, high PT $\left(35.5^{\circ}\right)$ and decreased LL $\left(11.8^{\circ}\right)$ and TK $\left(19.3^{\circ}\right)$. The increased PT (pelvic retroversion) and decreased
TK were mechanisms to compensate for sagittal imbalance. Cho et al. retrospectively analysed 45 patients who underwent long posterior instrumentation and fusion for adult lumbar degenerative scoliosis. Sagittal decompensation occurred in 19 patients (42\%) [24]. Compared with patients who were sagittally balanced after fusion, a high PI was the most significant risk for sagittal decompensation. This could be explained by a surgical undercorrection in patients with postoperative sagittal imbalance, because high PI needs more LL correction for proper sagittal balance [15].

The compensatory decrease of TK and increase of PT in patients with degenerative LL loss can spontaneously reverse after successful surgery, as reported in the retrospective study by Jang et al. [23]. In that study, 53 patients (mostly elderly women) with thoracic-compensated sagittal imbalance due to DSD underwent corrective lumbar surgery. Surgical restoration of LL was correlated with improvement of TK.

In the retrospective study by Gödde et al., 42 patients with spinal stenosis $(n=25)$ or degenerative segmental instability $(n=17)$ underwent PLIF with cages of various shapes [9]. When rectangular cages were used, global LL and segmental lordosis of the fused segments decreased, and sagittal balance was maintained by compensatory modifications of sacral tilt (or SS, which decreased from $44^{\circ}$ to $40^{\circ}$ ). Better results were obtained with wedge-shaped cages, with significant increase in segmental lordosis and LL; sacral tilt increased from $42^{\circ}$ to $45^{\circ}$. These results indicate the importance of taking into account parameters of sagittal balance to compare methods or devices for surgery of degenerative spinal pathologies.

Overall, these studies show that preoperative measurement of sagittal spinopelvic parameters is important, particularly in patients with high $\mathrm{PI}$, as they require a greater amount of LL restoration (up to $70-80^{\circ}$ ) for proper sagittal balance. The amount of global LL needed is approximately the following: $\mathrm{LL}(\mathrm{L} 1-\mathrm{S} 1)=\mathrm{PI}+9^{\circ}[24]$.

Sagittal balance parameters in surgery for LDDD with spondylolisthesis

Compared with the normal, asymptomatic population, patients with degenerative spondylolisthesis show higher PT and SS values, thus indicating pelvic compensation [25]. The retrospective study by Barrey et al. assessed sagittal balance parameters in 85 patients with three different types of LDDD (disc herniation, $n=25$; LDDD $n=32$; degenerative spondylolisthesis, $n=28$ ) and compared them with controls [26]. PI was average in patients with disc herniation $\left(49.8^{\circ}\right)$ and LDDD $\left(51.6^{\circ}\right)$ but was significantly higher in patients with degenerative spondylolisthesis $\left(60.0^{\circ}\right)$. Nevertheless, SS and LL were decreased in all three degenerative pathologies, an observation that is consistent with the study of Jackson et al. in patients with low back pain and described above [19]. Results for degenerative spondylolisthesis were extended by 
the same authors in a series of 40 patients [27]. These patients had a higher PI, which could be a predisposing factor of degenerative spondylolisthesis.

The retrospective pilot study by Kim et al. was the first to evaluate the impact of sagittal balance in 18 patients with degenerative spondylolisthesis who underwent fusion surgery [28]. The relationship between sagittal lumbar balance and clinical outcomes was assessed after PLIF for the relief of radicular leg and back pain. Patients were divided into two groups: those without postoperative improvement of PT value (group $\mathrm{A} ; n=10$ ) and those with improvement of postoperative PT value (group B; $n=8$ ). In group A, improvement of quality of life assessed using the visual analogue scale (VAS) was significantly correlated to postoperative LL $(r=-0.829$; $p=0.003)$; similarly, improvement in the Oswestry Disability Index (ODI) score was also positively correlated with postoperative LL $(r=-0.700 ; p=0.024)$. In group $\mathrm{B}$, VAS and improvement in ODI were not significantly correlated with postoperative LL or other spinopelvic parameters. In conclusion, this pilot study suggested that patients in whom PT improved after fusion achieved good clinical outcomes. These results also show that it is important to quantify sagittal spinopelvic parameters and promote sagittal balance when performing lumbar fusion for degenerative spondylolisthesis.

The purpose of the study by Funao et al. was to explore the spinopelvic sagittal alignment as a predisposing factor for degenerative spondylolisthesis. Spinopelvic sagittal alignment in patients with or without degenerative spondylolisthesis was analysed in 100 patients who underwent surgery for lumbar spinal canal stenosis. Fifty patients with degenerative spondylolisthesis (DS group) and 50 age- and gender-matched patients without degenerative spondylolisthesis (non-DS group) were compared. Several spinopelvic parameters (PI, SS, L4 slope, L5 slope, TK and LL) were significantly higher in the DS group; PI was correlated with slip rate in the DS group $(r=0.35, p<0.05)$. in whom PI was also more strongly correlated with SS ( $r=$ $0.82, p<0.001)$ than with PT $(r=0.41, p<0.01)$. In the nonDS group, PI was more strongly correlated with PT $(r=0.73, p$ $<0.001)$ than with SS $(r=0.38, p<0.01)$. These results suggest that progression of vertebral slip could be related to a greater PI; the compensatory mechanisms appear different between groups.

Sagittal balance parameters in surgery for degenerative scoliosis

Cohorts of patients analysed in the with adult deformities are often heterogeneous, including not only degenerative deformities but also adult idiopathic scoliosis or adolescent idiopathic scoliosis. Their common feature is the high rate of complications. The large retrospective study by Charosky et al. analysed risk factors in primary adult scoliosis patients after surgery [29]. A total of 306 patients with primary lumbar adult scoliosis or degenerative scoliosis patients were included; $39 \%$ had complications and $29 \%$ were reoperated for mechanical or neurological complications. Among the risk factors for complications was a preoperative $\mathrm{PT} \geq 26^{\circ}$. PT had been previously identified as a spinopelvic parameter correlated with health-related quality of life in the large prospective study of Lafage et al., who assessed 125 adult patients with spinal deformity (including 54 adult idiopathic scoliosis, 33 adult de novo scoliosis, 29 iatrogenic sagittal imbalance) [30]. High PT values, reflecting pelvic retroversion for compensation, were correlated with poor clinical outcome and quality of life (ODI, SF-12, Scoliosis Research Society).

The recent prospective study by Johnson et al. evaluated 30 patients with a mean age of 56 years with back pain and/or sciatica related to LDDD: 15 patients with degenerative scoliosis and 15 with lumbar spondylosis underwent fusion with minimally invasive techniques [31]. The aim of the study was to assess the effect of surgery on pelvic parameters related to sagittal balance. Before surgery, mean PI was $48.6^{\circ}$, with corresponding mean SS and PT of $32.0^{\circ}$ and $18.0^{\circ}$, respectively. Two and 6 months after surgery, quality of life assessed with VAS, ODI and SF-36 questionnaires were significantly improved. SS and PT were not significantly changed by surgery, and global LL was not modified $\left(n=22\right.$; from $42.8^{\circ}$ to $44.4^{\circ}$ ). Segmental lordosis $\left(n=31\right.$; from $3.0^{\circ}$ to $6.6^{\circ} ; p$ $<0.001)$ and lumbar scoliosis $\left(n=15\right.$; Cobb angle from $13.0^{\circ}$ to $7.1^{\circ} ; p=0.01$ ) were significantly improved. In conclusion, scoliosis and segmental lordosis were improved and were associated with significant clinical improvement; LL and pelvic parameters associated with sagittal balance were not significantly changed. However, it must be emphasised that in that study, scoliosis in the frontal plane was not completely corrected (only $50 \%$ reduction of Cobb angle); this could the reason for the lack of influence of surgery on pelvic parameters, which were not restored to normal values by surgery.

\section{Discussion and conclusion}

In recent years, there is growing literature regarding spinopelvic measurements in patients undergoing spinal surgery. In this literature review, we focused on surgery of LDDD, LDDD with spondylolisthesis and degenerative scoliosis. Spinal fusion in LDDD may result in loss of LL (flat back), with possible compensatory mechanisms: decreased SS and increased PT (indicating pelvic retroversion) compared with normal theoretical values for the same PI value [24, 26]; increased PT after surgery (pelvic retroversion) is correlated with postoperative pain [8, 12,32]. Patients with decreased SS and/or abnormal C7 plumb line after spinal fusion have a higher rate of adjacent-segment degeneration [21]. 
Therefore, it is necessary to assess before surgery the amount of LL that is required for optimal sagittal balance. High PI, which is a fixed anatomical parameter that does not change, appears to be a predicting factor of sagittal imbalance after spinal fusion $[32,33]$. Indeed, patients with high PI require more lumbar correction for sagittal balance and are frequently undercorrected, probably because it is more demanding technically to restore a high LL during surgery.

The compensatory mechanisms (pelvic retroversion with increased PT, decreased TK) for degenerative LL loss spontaneously reverse after successful surgery for $\operatorname{LDDD}[9,23]$ (Fig. 4). It is nevertheless important to emphasise that correction must be proportional to the PI value. In fact, mean PI values frequently reported in articles are useless without concomitant description of the classes of PI values (small, average, high) in the population analyses. Results of surgery in a series of surgical cases can be assessed only after analysis by classes. It is a general observation that patients with small PI and who require small lordosis have small variations in PT because the possibilities for pelvic retroversion are limited. This limitation is due to a low PI, which is an anatomical constant of the small pelvis [34]. This difference in the possibility of retroversion - and consequently of change in PT value - explains why mean values of a series of cases do not reflect clinical reality. Only restoring lordosis proportional to the PI value is essential.

In degenerative spondylolisthesis, few studies have focused on sagittal balance, especially PI, as a predictive factor. In degenerative spondylolisthesis, increased PT and decreased SS are frequent, thus indicating pelvic compensation. High PI appears to be a predictive factor of degenerative spondylolisthesis [26, 27, 35]. Improvement of postoperative PT is indicative of good clinical outcome [28].

In degenerative scoliosis, high preoperative PT, reflecting pelvic retroversion for compensation, is correlated with poor clinical outcome, quality of life and complications after surgery $[29,30]$. In patients with degenerative scoliosis, sagittal balance must be also taken into account for good clinical outcomes [31]. In the study by Johnson et al., improved scoliosis and segmental lordosis was associated with significant clinical improvement; LL and pelvic parameters associated with sagittal balance were not significantly changed. This apparent discrepancy is because parameter values were reported as mean and were not described by class. Indeed, in a
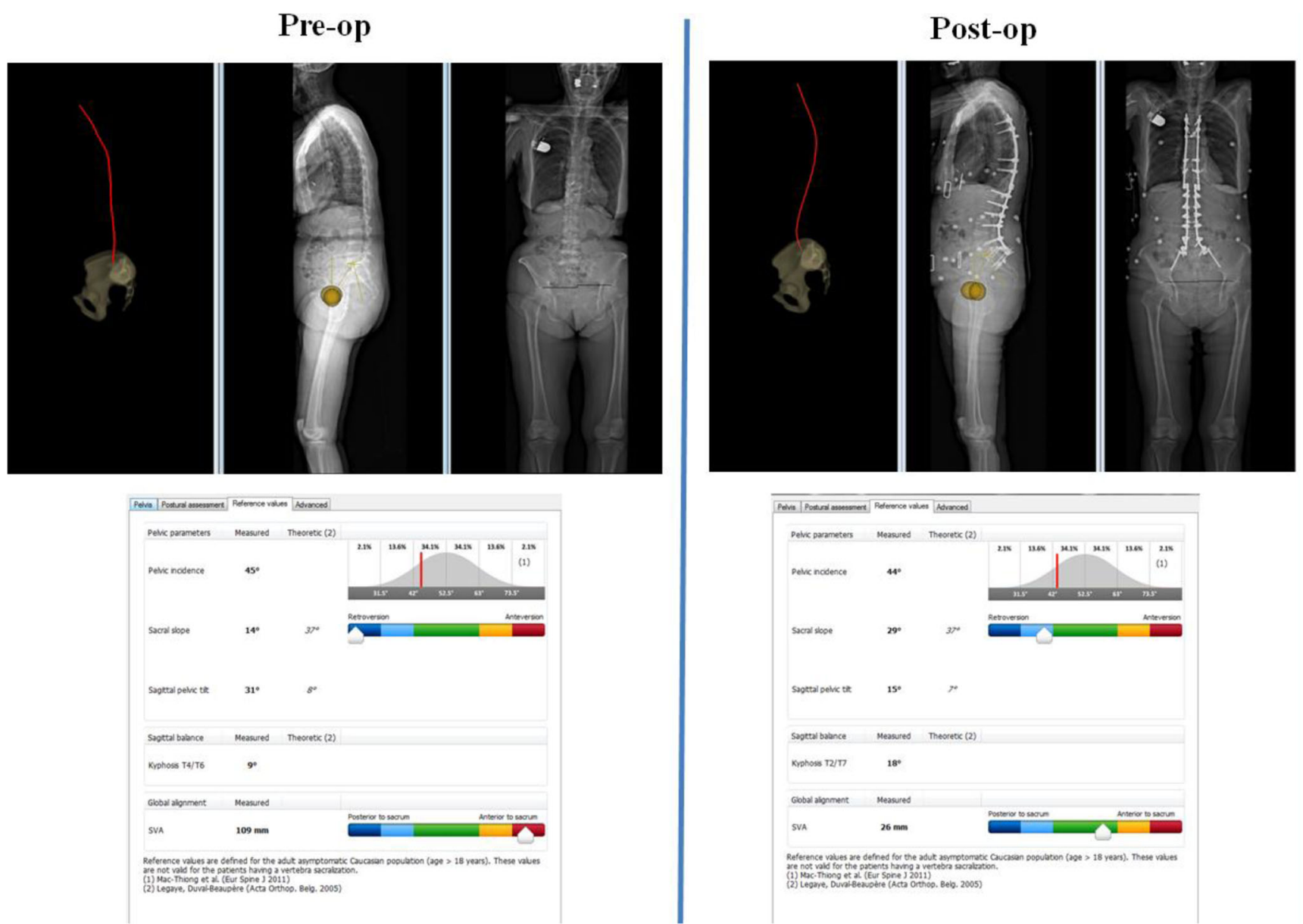

Fig 4 Surgery for lumbar degenerative disc disease (LDDD): a Preoperative and b postoperative radiographs and postural assessment analysis (EOS Imaging, Paris, France) of a patient whose surgery was successful 
normal population, when PI is low, PT and SS are low; conversely, when PI is high, PT and SS are high. These variations in PI are simply the consequence of the Gaussian distribution of a given parameter in a population. The mean value in a group of patients is useless; only comparison with the theoretical value of one class of PI measured in a normal asymptomatic population is the correct way to analyse measurements of the same parameter before and after surgery. Thus, a PI of $40^{\circ}$ is normally associated with a PT of $8^{\circ}$ and a PI of $70^{\circ}$ is normally associated with a PT of $20^{\circ}$ in a normal asymptomatic population. This explains why, in the article by Johnson et al., LL and pelvic indices associated with sagittal balance were not significantly changed [31].

Most studies included in this literature review were, however, most often retrospective, noncomparative, had small numbers of patients and frequently reported radiographic parameters only. Therefore, there is a need for comparative prospective studies including pre- and postoperative measurements of sagittal balance and correlations with complications, degree of disability, pain and quality of life. Nevertheless, the importance of compensatory changes in pelvic attitude and their possible functional consequences on sagittal balance are widely recognised.

In conclusion, measuring the radiographic spinopelvic parameters of sagittal balance in order to prevent functional disability is now a routine part of many interventions for degenerative spinal diseases. Of importance, the theoretical PT and SS values for a given PI value must be known before the intervention in order to perioperatively restore the appropriate LL value. Only LL restoration will allow the pelvis to rotate forward to return to the normal theoretical PT and SS values, because PI is a constant anatomical parameter.

Acknowledgments The authors acknowledge Sergio Quijano for English translation.

\section{Conflict of interest statement None.}

Open AccessThis article is distributed under the terms of the Creative Commons Attribution License which permits any use, distribution, and reproduction in any medium, provided the original author(s) and the source are credited.

\section{References}

1. Lotz JC, Haughton V, Boden SD et al (2012) New treatments and imaging strategies in degenerative disease of the intervertebral disks. Radiology 264:6-19

2. Sasiadek MJ, Bladowska J (2012) Imaging of degenerative spine disease-the state of the art. Adv Clin Exp Med 21:133-142

3. O'Shaughnessy BA, Ondra SL (2007) Measuring, preserving, and restoring sagittal spinal balance. Neurosurg Clin N Am 18:347-356

4. Vedantam R, Lenke LG, Keeney JA, Bridwell KH. 1998 Comparison of standing sagittal spinal alignment in asymptomatic adolescents and adults. Spine (Phila Pa 1976);23:211-215.
5. Vaz G, Roussouly P, Berthonnaud E, Dimnet J (2002) Sagittal morphology and equilibrium of pelvis and spine. Eur Spine J 11: 80-87

6. Hammerberg EM, Wood KB (2003) Sagittal profile of the elderly. J Spinal Disord Tech 16:44-50

7. Gelb DE, Lenke LG, Bridwell KH, Blanke K, McEnery KW.1995 An analysis of sagittal spinal alignment in 100 asymptomatic middle and older aged volunteers. Spine (Phila Pa 1976); 20:1351-1358.

8. Lazennec JY, Ramare S, Arafati N et al (2000) Sagittal alignment in lumbosacral fusion: relations between radiological parameters and pain. Eur Spine J 9:47-55

9. Godde S, Fritsch E, Dienst M, Kohn D.2003 Influence of cage geometry on sagittal alignment in instrumented posterior lumbar interbody fusion. Spine (Phila Pa 1976).;28:1693-1699.

10. Goldstein JA, Macenski MJ, Griffith SL, McAfee PC. 2001 Lumbar sagittal alignment after fusion with a threaded interbody cage. Spine (Phila Pa 1976).; 26: 1137-1142.

11. Stephens GC, Yoo JU, Wilbur G. 1996 Comparison of lumbar sagittal alignment produced by different operative positions. Spine (Phila Pa 1976).; 21:1802-1806; discussion 1807.

12. Tribus CB, Belanger TA, Zdeblick TA.1999 The effect of operative position and short-segment fusion on maintenance of sagittal alignment of the lumbar spine. Spine (Phila Pa 1976).; 24:58-61.

13. Faundez A, Roussouly P (2011) Le Huec JC [Sagittal balance of the spine: a therapeutic revolution]. Rev Med Suisse 7:2470-2474

14. Johnson RD, Valore A, Villaminar A, Comisso M, Balsano M (2013) Sagittal balance and pelvic parameters-a paradigm shift in spinal surgery. J Clin Neurosci 20:191-196

15. Le Huec JC, Charosky S, Barrey C, Rigal J, Aunoble S (2011) Sagittal imbalance cascade for simple degenerative spine and consequences: algorithm of decision for appropriate treatment. Eur Spine J 20(Suppl 5):699-703

16. Mehta VA, Amin A, Omeis I, Gokaslan ZL, Gottfried ON (2012) Implications of spinopelvic alignment for the spine surgeon. Neurosurgery 70:707-721

17. Roussouly P, Gollogly S, Berthonnaud E, Dimnet J.2005 Classification of the normal variation in the sagittal alignment of the human lumbar spine and pelvis in the standing position. Spine (Phila Pa 1976).;30:346-353.

18. Janik TJ, Harrison DD, Cailliet R, Troyanovich SJ, Harrison DE (1998) Can the sagittal lumbar curvature be closely approximated by an ellipse? J Orthop Res 16:766-770

19. Jackson RP, McManus AC.1994 Radiographic analysis of sagittal plane alignment and balance in standing volunteers and patients with low back pain matched for age, sex, and size. A prospective controlled clinical study. Spine (Phila Pa 1976).;19:1611-1618.

20. Barrey C, Roussouly P, Le Huec JC, D'Acunzi G, Perrin G (2013) Compensatory mechanisms contributing to keep the sagittal balance of the spine. Eur Spine J 22(Suppl 6):S834-841

21. Kumar M, Baklanov A, Chopin D (2001) Correlation between sagittal plane changes and adjacent segment degeneration following lumbar spine fusion. European Spine Journal 10:314-319

22. Kawakami M, Tamaki T, Ando M, Yamada H, Hashizume H, Yoshida M.2002 Lumbar sagittal balance influences the clinical outcome after decompression and posterolateral spinal fusion for degenerative lumbar spondylolisthesis. Spine (Phila Pa 1976).;27: $59-64$.

23. Jang JS, Lee SH, Min JH, Maeng DH. 2009 Influence of lumbar lordosis restoration on thoracic curve and sagittal position in lumbar degenerative kyphosis patients. Spine (Phila Pa 1976);34:280-284.

24. Schwab F, Lafage V, Patel A, Farcy JP. 2009 Sagittal plane considerations and the pelvis in the adult patient. Spine (Phila Pa 1976).; 34: $1828-1833$.

25. Chaleat-Valayer E, Mac-Thiong JM, Paquet J, Berthonnaud E, Siani F, Roussouly P (2011) Sagittal spino-pelvic alignment in chronic low back pain. Eur Spine J 20(Suppl 5):634-640 
26. Barrey C, Jund J, Noseda O, Roussouly P (2007) Sagittal balance of the pelvis-spine complex and lumbar degenerative diseases. A comparative study about 85 cases. Eur Spine J 16: 1459-1467

27. Barrey C, Jund J, Perrin G, Roussouly P (2007) Spinopelvic alignment of patients with degenerative spondylolisthesis. Neurosurgery 61:981-986, discussion 986

28. Kim MK, Lee SH, Kim ES, Eoh W, Chung SS, Lee CS (2011) The impact of sagittal balance on clinical results after posterior interbody fusion for patients with degenerative spondylolisthesis: a pilot study. BMC Musculoskelet Disord 12:69

29. Charosky S, Guigui P, Blamoutier A, Roussouly P, Chopin D.2012 Complications and risk factors of primary adult scoliosis surgery: a multicenter study of 306 patients. Spine (Phila Pa 1976).;37:693-700.

30. Lafage V, Schwab F, Patel A, Hawkinson N, Farcy JP. 2009 Pelvic tilt and truncal inclination: two key radiographic parameters in the setting of adults with spinal deformity. Spine (Phila Pa 1976).;34: E599-606.

31. Johnson RD, Valore A, Villaminar A, Comisso M, Balsano M (2013) Pelvic parameters of sagittal balance in extreme lateral interbody fusion for degenerative lumbar disc disease. J Clin Neurosci 20: 576-581

32. Gottfried ON, Daubs MD, Patel AA, Dailey AT, Brodke DS (2009) Spinopelvic parameters in postfusion flatback deformity patients. Spine J 9:639-647

33. Cho KJ, Suk SI, Park SR, et al.2010 Risk factors of sagittal decompensation after long posterior instrumentation and fusion for degenerative lumbar scoliosis. Spine (Phila Pa 1976).;35:1595-1601.

34. Roussouly P, Pinheiro-Franco JL (2011) Sagittal parameters of the spine: biomechanical approach. Eur Spine J 20(Suppl 5):578-585

35. Funao H, Tsuji T, Hosogane N et al (2012) Comparative study of spinopelvic sagittal alignment between patients with and without degenerative spondylolisthesis. Eur Spine J 21:2181-2187 